\title{
Statistical Lament (after Joni Mitchell)
}

\section{Robert J. MacG. Dawson}

Rows and flows of lines and spots,

Histograms and digidots,

Box-and-whiskers, quantile plots:

I've looked at stats that way.

But is it just a picture show?

If something's there how will you know?

And if they say it isn't so

What is there left to say?

I've looked at plots from both sides now,

Transformed and spun them: still, somehow,

It's plots' illusions I recall,

I really can't trust plots at all.

Dainty ladies tasting teas

Rejecting null hypotheses

At standard probabilities:

I've looked at stats that way.

But is it just a lottery?

At four percent they all agree;

At six percent the referee

Says "take this junk away."

I've looked at tests from both sides now:

Retain, reject - and still somehow

I look at tests and I recall

I really can't accept at all.

Ways of Bayes and likelihood,

We'll teach the things we know we should,

The True, the Beautiful, the Good

And blow the clouds away.

But now my class are acting strange,

They tell the Dean that I'm deranged

And that they need (till customs change)

Their tests and EDA.

From both sides now I've looked Bayes o'er,

Both prior and posterior:

It's mass confusion I recall,

I really can't teach Bayes, at all. 